\title{
Observability Increases the Demand for Commitment Devices
}

\section{Citation}

Exley, Christine L., and Jeffrey K. Naecker. "Observability Increases the Demand for Commitment Devices." Management Science 63, no. 10 (October 2017): 3262-3267. doi:10.1287/ mnsc.2016.2501.

\section{Published Version}

doi:10.1287/mnsc.2016.2501

\section{Permanent link}

http://nrs.harvard.edu/urn-3:HUL.InstRepos:37101499

\section{Terms of Use}

This article was downloaded from Harvard University's DASH repository, and is made available under the terms and conditions applicable to Open Access Policy Articles, as set forth at http:// nrs.harvard.edu/urn-3:HUL.InstRepos:dash.current.terms-of-use\#OAP

\section{Share Your Story}

The Harvard community has made this article openly available.

Please share how this access benefits you. Submit a story.

Accessibility 


\title{
Observability Increases the Demand for Commitment Devices
}

\author{
Christine L. Exley and Jeffrey K. Naecker*
}

March 4, 2016

\begin{abstract}
Previous research often interprets the choice to restrict one's future opportunity set as evidence for sophisticated time-inconsistency. We propose an additional mechanism that may contribute to the demand for commitment technology: the desire to signal to others. We present a field experiment where participants can choose to give up money if they do not follow through with an action. When commitment choices are made public rather than kept private, we find significantly higher uptake rates.
\end{abstract}

JEL: C93, D91

Keywords: field experiment; commitment; signaling; time inconsistency

*Exley (corresponding author): Negotiation, Organizations and Markets Unit Harvard Business School, Baker Library 449, Boston MA 02163; clexley@hbs.edu. Naecker: Wesleyan University, Department of Economics, PAC 123, 238 Church Street, Middletown, CT 06459-0007, USA; jnaecker@wesleyan.edu. Acknowledgements: Christine Exley gratefully acknowledges funding for this study from the NSF (SES1159032). For helpful advice, both authors would like to thank participants at the Stanford Behavioral Lunch, the Experimental Sciences Association Annual Conference, the Bay Area Behavioral and Experimental Economics Workshop, as well as B. Douglas Bernheim, Muriel Niederle, Al Roth, P.J. Healy, and Charles Sprenger. We would also like to thank the many people at Stanford's Haas Center for Public Service for partnering with us on this work, particularly Kristen Azevedo. 


\section{Introduction}

In many settings, economic agents are observed restricting their future opportunity sets without being compensated (see overviews by Milkman, Rogers and Bazerman (2008) and Bryan, Karlan and Nelson (2010)). Such behavior is generally considered irreconcilable with a time-consistent discounted expected utility model. One popular explanation for this "deliberate regimenting of one's future economic behavior" is that individuals have timeinconsistent preferences (Strotz, 1955). An agent who is (at least partially) aware of her own time-inconsistent preferences may seek to restrict her future options - that is, show a demand for commitment - so as to avoid self-damaging activities or pursue desirable behavior. ${ }^{1}$ For example, they may seek to commit themselves to increase their savings (Thaler and Benartzi, 2004; Ashraf, Karlan and Yin, 2006; Kast, Meier and Pomeranz, 2012; Dupas and Robinson, 2013), avoid procrastination (Ariely and Wertenbroch, 2002; Duflo, Kremer and Robinson, 2011), exercise more often (DellaVigna and Malmendier, 2006; Milkman, Minson and Volpp, 2013), work harder or longer (Kaur, Kremer and Mullainathan, 2010; Houser et al., 2010), quit smoking (Giné, Karlan and Zinman, 2010) or donate more to charity (Breman, 2011).

This paper proposes an additional mechanism that may contribute to the desire for restricting one's future opportunity sets: individuals may view their choices to uptake commitment devices as signaling mechanisms. ${ }^{2}$ Individuals may demand restrictive savings devices to signal financial responsibility, set punishing deadlines to signal highly valuing their work, or buy gym memberships to signal health conscientiousness, among other possibilities. Individuals who value such signaling may therefore demand commitment devices even if they fully intend not to follow-through - indeed this could contribute to the often observed losses from demanded commitment. ${ }^{3}$

In considering signaling motivations related to commitment devices, we join a robust literature that considers the returns from commitment devices that may rely on peer pressure.

\footnotetext{
${ }^{1}$ For a theoretical model that considers the implications of whether an agent is naive or sophisticated about their own time-inconsistency, see O'Donoghue and Rabin (1999).

${ }^{2}$ There is a robust theoretical and empirical literature related to individuals' desires to signal positive attributes about themselves - such as their status (Bernheim, 1994), their generosity (Andreoni and Petrie, 2004; Bénabou and Tirole, 2006; Ariely, Bracha and Meier, 2009), or adherence to fairness norms (Andreoni and Bernheim, 2009) - and to avoid signaling negative attributes about themselves - such as appearing greedy (Ariely, Bracha and Meier, 2009; Exley, 2015). The literature on conspicuous consumption also tells us that people are willing to spend money to signal their wealth or social status (Ireland, 1994; Bagwell and Bernheim, 1996; Hopkins and Kornienko, 2004; Amaldoss and Jain, 2005).

${ }^{3}$ An alternative to commitment devices, where such losses are possible, is providing positive incentives to help overcome potentially time-inconsistent behavior, such as in Charness and Gneezy (2009). For a theoretical consideration of the tradeoffs between positive incentives and punishments or commitment devices, see Peysakhovich (2014).
} 
For example, Gugerty (2007) summarizes the common refrain of women involved in group savings schemes in their title - you can't save alone - and Dupas and Robinson (2013) document how related social motivations can crucially help the poor save more. Kast, Meier and Pomeranz (2012) show that even announcing one's personal savings goals to peers goals that do not financially influence said peers - can be effective. ${ }^{4}$

This study departs from the literature by holding fixed the observability of whether individuals follow-through with their choices. ${ }^{5}$ To narrow in on the signaling motivations arising from commitment choices themselves, this study instead examines how individuals' demand for commitment depends on whether the commitment choice itself is privately held or publicly known.

In particular, our field experiment offers undergraduate students a commitment choice when they sign up to attend a workshop offered by an on-campus center that focuses on public service and leadership: students can choose to give up any dollar amount from $\$ 0$ to $\$ 15$ if they do not show up. Their decisions to sign-up and to attend the workshop are always observed by the person running the workshop. Their chosen level of commitment is only known to themselves in the private treatment, but additionally revealed to the person running the workshop in the public treatment.

Commitment behavior is markedly different in the private and public treatments. In the private treatment, $41 \%$ of the participants demand some commitment - they are willing to forgo at least $\$ 1$ if they do not attend the workshop - and the average commitment level chosen is $\$ 5.17$. In the public treatment, the demand for commitment substantially increases: $65 \%$ of participants demand some commitment and the average commitment level chosen is $\$ 8.87$. We view this finding as evidence that observability conditions of commitment choices influence the demand for commitment; the demand for commitment may not imply a desire to overcome time-inconsistent behavior if signaling motivations are relevant.

Our findings highlight the importance of carefully considering the role for signaling motivations when interpreting results or designing future studies related to commitment choices. Of course, the particular social context of the choice environment and underlying preferences of the individuals - such as the desire to appear financially adept, smart, healthy, nice, ethical, or committed itself - may dictate which signaling pathways are relevant. As

\footnotetext{
${ }^{4}$ Kast, Meier and Pomeranz (2012) also find a similar effectiveness of feedback absent any peer monitoring, showing that peer monitoring is not necessary and the effectiveness thereof may in part result from conveying feedback.

${ }^{5}$ Prior literature largely focuses on varying the observability of both commitment choices and followthrough, or on the observability of follow-through only.
} 
such, we view further investigation into separately identifying these potential signaling motivations related to commitment choices as a fruitful avenue for future work. Furthermore, if commitment is preferable from a normative point of view, as it may be in some settings (Milkman, Rogers and Bazerman, 2008), our research highlights the potentially powerful leverage of manipulating the observability of individuals' commitment decisions in order to achieve socially desirable outcomes.

\section{Design}

Stanford University's Haas Center for Public Service offers a series of workshops that are intended for current Stanford students to "gain exposure, knowledge, and skills on a variety of public service topics and issue areas." 6 These workshops are free for students, last between 60 and 120 minutes, and typically occur during lunch or dinner time. The Haas Center requests that students sign up for workshops so that they can make the appropriate arrangements. As many students fail to show up, the Haas Center frequently incurs wasteful costs from too much food or materials.

We conducted a field experiment that manipulated the sign-up process for thirteen workshops offered during the winter quarters (January through March) of 2013 and 2014. ${ }^{7}$ In order to sign up for workshops, students had to complete an online form. The first page of the form gathered information requested by the Haas Center, such as the student's name and meal preferences. After also indicating which workshop or workshops they intended to attend, students proceeded onto a second page in the sign-up process. ${ }^{8}$

In all treatments, the second page reminded them of the location and time of the work$\operatorname{shop}(\mathrm{s})$ they signed up for. It also informed them that a grant had provided them with the possibility of earning some money for attending the workshop. Students learned that this grant was research-related only via a follow-up survey that was sent to them after the date for their treatment workshop had passed.

In the control treatment, no commitment device was offered. Students were instead

\footnotetext{
${ }^{6}$ See http://studentaffairs.stanford.edu/haas/students/workshops for more information.

${ }^{7}$ The Haas Center selected the thirteen workshops for this study. In Winter 2013, this included all ten of the workshops they had planned at the beginning of the quarter, plus one additional workshop that was added later in the quarter. In Winter 2014, this included two out of the seven workshops that were planned at the beginning of the quarter. The Haas Center expected these two selected workshops to have the highest attendance. In both the Winter 2013 and Winter 2014, other workshops were added later in the quarter that were not involved in our study.

${ }^{8}$ In total, there were four versions of the online form used to gather sign-ups for these workshops. Three of the versions only allowed students to sign up for one particular workshop, which by default is their treated workshop. The fourth version allowed students to sign-up for any number of ten different workshops.
} 
informed that they would (unconditionally) receive a $\$ 15$ Amazon gift card. By contrast, in the public and private treatments, students were offered a simple commitment device to attend one workshop. If they had only signed up for one workshop, then their commitment device applied to that workshop. If they had signed up for more than one workshop, then their commitment device applied to a random selection of one of their workshops. The commitment technology was implemented as follows: students were told that they would receive a $\$ 15$ Amazon gift card if they attended the workshop. If they did not attend, they would receive an Amazon gift card worth $\$ X$. Students chose their value of $X$ to be equal to any whole dollar value between $\$ 0$ to $\$ 15$, inclusive. Higher values of $X$, therefore, implied lower levels of commitment. For instance, if a student chose $X=15$, then they made no commitment; they would receive $\$ 15$ regardless of whether or not they attended their treatment workshop. By contrast, if a student chose $X=0$, then they demanded maximal commitment; they would receive $\$ 0$, forgoing the entire $\$ 15$ payment, if they did not attend their workshop. When choosing their $X$, students were also informed that the granting institution, not the Haas Center, would receive any money left over from this $\$ 15$ offer.

The commitment device offered in the public and private treatments only differed in one key dimension: the observability of $X$. In the private treatment, students were told that their chosen $X$ would be kept anonymous and not shared with anyone involved with running the Haas Center workshops. By contrast, in the public treatment, students were told that their name and corresponding choice of $X$ would be shared with the Haas Program Director of Student Organizations and Leadership, who oversees the workshops. ${ }^{9}$

As is standard with these workshops to ensure proper allotments of food and other materials, the names and dietary needs of students who signed up for the workshop were passed onto the Haas Program Director. This list was also used by the Haas Program Director to send out reminder emails and record workshop attendance. Thus, the observability of participants' attendance was constant across all treatments. All that varied was whether commitment was offered (control versus public and private treatments) and whether the commitment choice was observable (private versus public treatment). Table 1 provides a summary of our three treatments; see Appendix Figures A.1 - A.3 for sample screenshots of each treatment group.

\footnotetext{
${ }^{9}$ The Haas Program Director noted that he/she personally knew most students who signed-up for these workshops, as they tended to be student leaders and thus were involved with the Haas Center in other ways.
} 
Table 1: Summary of the key design elements for each treatment

\begin{tabular}{lccc}
\hline \hline & \multicolumn{2}{c}{ Value of Amazon Gift Card If Student: } & \\
& Attended Workshop & Did Not Attend Workshop & Commitment Choice \\
\hline Control & $\$ 15$ & $\$ 15$ & None \\
Private & $\$ 15$ & $\$ X$ & choose $X$ (privately) \\
Public & $\$ 15$ & $\$ X$ & choose $X$ (publicly) \\
\hline \hline
\end{tabular}

\section{Results}

Eighty-six undergraduate students participated in our study. We exclude six students: one due to not completing the workshop sign-up process and five due to completing the workshop sign-up process multiple times. This leaves us with eighty Stanford undergraduate students in our sample. Since responses to a follow-up survey (sent after the date of treatment workshops) exist for less than $10 \%$ of students, no demographic information will be included in our analysis. The main data, resulting from random assignment to one of the three treatments with lower weight placed on the control, includes 29 observations in the private treatment, 31 in the public treatment, and 20 in the control treatment. ${ }^{10}$

Recall that in all treatments, payments equal $\$ 15$ if students attend their workshop. In the control group, payments also equal $\$ 15$ if students do not attend their workshop. However, in the public and private treatments, payments equal $\$ X$ if students do not attend their workshop. Since the $X$ values are chosen by the students, we present results in terms of chosen level of commitment $C=15-X$.

Figure 1 shows the distribution of commitment choices and Table 2 provides related descriptive statistics for the public and private treatments. If signaling motivations do not influence a student's desire to demand commitment, differences in commitment choices should not arise across the public and private treatments. This is clearly not the case.

When students' commitment choices are private, the average commitment level chosen is $\$ 5.17$. When students' commitment choices are instead public, the average increases to \$8.87. This $50 \%$ increase mirrors the increase in fraction of students who choose some commitment $(C>0)$ or maximal commitment $(C=15)$. In moving from the private to public treatment, the fraction choosing some commitment increases from $41 \%$ to $65 \%$ while the fraction choosing maximal commitment increases from $31 \%$ to $55 \%$. The statistical

\footnotetext{
${ }^{10}$ One of the thirteen workshops in this study has no student sign-ups. Six workshops have exactly the same number of students in the private and public treatments. The number of students in the private and public treatments differs by no more than three in the remaining workshops.
} 
Figure 1: Distribution in chosen level of commitment

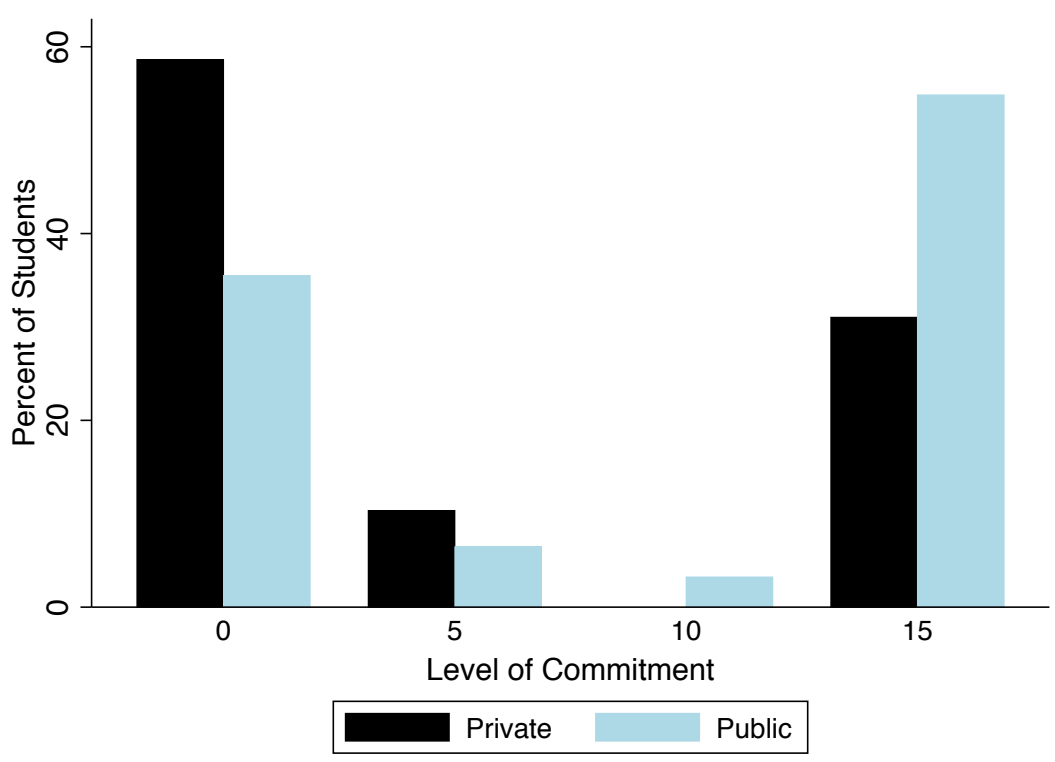

Distribution of the level of commitment chosen by each student, plotted separately for the public and private treatments. Students could choose any whole dollar value between $\$ 0$ and $\$ 15$, even though only multiples of $\$ 5$ occur. The data set is the 60 students in the private or public treatments.

significance of these differences are reported via $p$-values in Table 2 and the regression results in Appendix Table A.1. Notably, the results appear stronger when including workshop fixed effects and controlling for the number of workshops for which a student signs-up. ${ }^{11}$

Despite being able to choose any whole dollar amounts from $\$ 0$ to $\$ 15$, nearly all students in both the public and private treatments choose the extreme values of no commitment or maximal commitment. It follows that, among students who demand commitment, the average commitment level is similar: $\$ 12.50$ in the private treatment and $\$ 13.75$ in the public treatment. Table 2 and the regression results in Table A.1 indeed show that there are no statistically significant differences on this measure. In other words, the increase in the demand for commitment appears to be driven by an extensive margin shift from nonexistent to maximal commitment.

We interpret our results as highlighting the importance of signaling motivations in explaining the demand for commitment. Our experiment is not designed to determine exactly which signaling pathways are active, but it does suggests that this question is ripe for for

\footnotetext{
${ }^{11}$ Additional subgroup analyses, for instance by examining if students who sign-up for more workshops respond more strongly to the treatment effects, are not feasible due to our small sample size.
} 
Table 2: Descriptive Statistics on Commitment Choices

\begin{tabular}{|c|c|c|c|}
\hline & $\begin{array}{c}\text { Private } \\
\text { Commitment }\end{array}$ & $\begin{array}{c}\text { Public } \\
\text { Commitment }\end{array}$ & $\begin{array}{l}\text { P-Value of } \\
\text { Difference }\end{array}$ \\
\hline Average $C$ & 5.17 & 8.87 & 0.046 \\
\hline Fraction with $C>0$ & 0.41 & 0.65 & 0.073 \\
\hline Fraction with $C=15$ & 0.31 & 0.55 & 0.063 \\
\hline Average $C$, given $C>0$ & 12.50 & 13.75 & 0.367 \\
\hline Observations & 29 & 31 & 60 \\
\hline
\end{tabular}

The $p$-values for the first and fourth rows are from two-sided t-tests. The $p$-values for the second and third rows are from two-sided tests of proportions.

further investigation. In the remainder of this section, we speculate about potential signaling channels, guided by suggestive data from our workshop attendance results and (very limited) follow-up responses.

In the control treatment, where no commitment device is offered, $55 \%$ of students attend the workshop. Offering a private commitment device, despite $41 \%$ of students choosing to partake in it, does not result in higher attendance: only $52 \%$ attend. Offering a public commitment device appears slightly more promising with the attendance rate increasing to $58 \%$, but this increase is not statistically different than the control or private treatment. ${ }^{12}$

Not surprised by the poor attendance rates, the Haas Center proposed a plausible explanation: Stanford undergraduate students, in particular the student leaders for whom these workshops are intended, are well aware of their overbooked schedules. They expect that a higher priority commitment may, with some chance, override their ability to attend workshops at the Haas Center despite their best efforts. The responses of the eight students who missed a workshop and explain their absence in the follow-up survey are consistent with this possibility. The only reasons mentioned are sickness, forgetfulness, and being unexpectedly busy due to a class running over time or a homework assignment requiring more time. In the words of one student "I did not attend the workshop [...] because I had an assignment due at noon and I needed the extra time to review my work prior to submission."

If students do not expect their available time to be a binding constraint, then more commitment demand in the public treatment could reflect (partially) sophisticated timeinconsistent students believing that the signaling component of their commitment choice

\footnotetext{
${ }^{12}$ Although selection prohibits potential inferences, it is also interesting to note that there are no significant differences in attendance rates between students who demand no commitment and those who demand some commitment in the private treatment ( $53 \%$ vs $50 \%$ ) or the public treatment (64\% vs $55 \%$ ).
} 
would help ensure their attendance. The lack of significant attendance results may then reflect inaccurate expectations. Alternatively, if students expect their available time to be a binding constraint, they may demand more commitment in the public treatment because they desire to signal to the Haas Center their value of the workshop, particularly if attendance turns out to be infeasible. In other words, students may desire to "pay not to attend" not necessarily as an excuse not to attend but instead to appear more favorably to the Haas Center if they cannot attend. ${ }^{13}$

Higher commitment demand when choices are public may additionally reflect other signaling motives, such as a desire to appear committed, not greedy, or not unethical. ${ }^{14}$

\section{Conclusion}

In our field experiment, the fraction of students demanding commitment and the average commitment level both increase by over $50 \%$ if commitment choices are public. As signaling can thus be a driving force in commitment choices, it is important to consider the demand for commitment not only as evidence for a desire to overcome time inconsistency. Doing otherwise may lead to an incomplete understanding of individuals' time preferences.

When structuring commitment devices, the role of signaling gives rise to several additional considerations. On one hand, if encouraging more commitment is desirable, then increasing the observability of commitment decisions, as in our study, may serve as a cost-effective policy tool. On the other hand, such a policy may warrant an additional caution. If individuals demand commitment in order to achieve some signaling payoff, even though this commitment does not help them to overcome time-inconsistent behavior, they may suffer a financial loss from the restriction of their future opportunity set. ${ }^{15}$ In considering these possibilities, future work may seek to separately identify the particular signaling motivations related to the demand for commitment.

\footnotetext{
${ }^{13}$ Charness and Dufwenberg (2006) provide evidence of guilt aversion that results from not wanting to disappoint others. A similar story may result from not wanting to disappoint oneself, though small financial rewards and punishment may crowd out intrinsic motivation, as shown in Gneezy and Rustichini (2000a,b).

${ }^{14}$ For papers related to a desire not to appear greedy, see Bénabou and Tirole (2006) and Ariely, Bracha and Meier (2009). For papers that consider whether individuals desire to avoid appearing unethical, either for economic or purely image motives, see Fischbacher and Föllmi-Heusi (2013) or Nagin et al. (2002).

${ }^{15}$ Relative to the private treatment, the average financial loss in the public treatment is indeed $34 \%$ larger, although insignificantly so. In particular, the average loss in the private treatment is $-\$ 2.76$ and in the public treatment is $-\$ 3.71$. Although not significantly different than each other, they are both significantly less than $\$ 0(p=0.016$ for the private treatment and $p=0.003$ for the public treatment).
} 


\section{References}

Amaldoss, Wilfred, and Sanjay Jain. 2005. "Conspicuous Consumption and Sophisticated Thinking." Management Science, 51: 1449-1466.

Andreoni, James, and B. Douglas Bernheim. 2009. "Social Image and the 50-50 Norm: A Theoretical and Experimental Analysis of Audience Effects." Econometrica, 77(5): 1607-1636.

Andreoni, James, and Ragan Petrie. 2004. "Public goods experiments without confidentiality: a glimpse into fund-raising." Journal of public Economics, 88(7): 1605-1623.

Ariely, Dan, Anat Bracha, and Stephan Meier. 2009. "Doing Good or Doing Well? Image Motivation and Monetary Incentives in Behaving Prosocially." American Economic Review, 99(1): 544-555.

Ariely, Dan, and Klaus Wertenbroch. 2002. "Procrastination, Deadlines, and Performance: Self-Control by Precommitment." Psychological Science, 13(3): 219-224.

Ashraf, Nava, Dean Karlan, and Wesley Yin. 2006. "Tying Odysseus to the Mast: Evidence from a Commitment Savings Product in the Philippines." The Quarterly Journal of Economics, 121(2): 635-672.

Bagwell, Laurie Simon, and B Douglas Bernheim. 1996. "Veblen Effects in a Theory of Conspicuous Consumption." American Economic Review, 86(3): 349-73.

Bénabou, Roland, and Jean Tirole. 2006. "Incentives and Prosocial Behavior." American Economic Review, 96(5): 1652-1678.

Bernheim, B. Douglas. 1994. "A Theory of Conformity." Journal of Political Economy, 102(5): pp. 841-877.

Breman, Anna. 2011. "Give more tomorrow: Two field experiments on altruism and intertemporal choice." Journal of Public Economics, 95(11): 1349-1357.

Bryan, Gharad, Dean Karlan, and Scott Nelson. 2010. "Commitment Devices." $A n$ nual Review of Economics, 2(1): 671-698.

Charness, Gary, and Martin Dufwenberg. 2006. "Promises and Partnership." Econometrica, 74(6): 1579-1601. 
Charness, Gary, and Uri Gneezy. 2009. "Incentives to Exercise." Econometrica, 77(3): 909-931.

DellaVigna, Stefano, and Ulrike Malmendier. 2006. "Paying not to go to the gym." The American Economic Review, 694-719.

Duflo, Esther, Michael Kremer, and Jonathan Robinson. 2011. "Nudging farmers to use fertilizer: Theory and experimental evidence from Kenya." American Economic Review, 101(6): 2350-2390.

Dupas, Pascaline, and Jonathan Robinson. 2013. "Why Don't the Poor Save More? Evidence from Health Savings Experiments." American Economic Review, 103(4): 113871.

Exley, Christine L. 2015. "Incentives for Prosocial Behavior: The Role of Reputations." Working Paper.

Fischbacher, Urs, and Franziska Föllmi-Heusi. 2013. "Lies in Disguise - An Experimental Study on Cheating." Journal of the European Economic Association, 11(3): 525-547.

Giné, Xavier, Dean Karlan, and Jonathan Zinman. 2010. "Put your money where your butt is: a commitment contract for smoking cessation." American Economic Journal: Applied Economics, 213-235.

Gneezy, Uri, and Aldo Rustichini. 2000a. "A Fine is A Price." The Journal of Legal Studies, 24.

Gneezy, Uri, and Aldo Rustichini. 2000b. "Pay Enough or Don't Pay at All." Quarterly Journal of Economics, 115(3): 791-810.

Gugerty, Mary Kay. 2007. "You Can't Save Alone: Commitment in Rotating Savings and Credit Associations in Kenya." Economic Development and Cultural Change, 55: 251-282.

Hopkins, Ed, and Tatiana Kornienko. 2004. "Running to Keep in the Same Place: Consumer Choice as a Game of Status." American Economic Review, 94(4): 1085-1107.

Houser, Daniel, Daniel Schunk, Joachim K. Winter, and Erte Xiao. 2010. "Temptation and Commitment in the Laboratory." Working Paper. 
Ireland, Norman J. 1994. "On limiting the market for status signals." Journal of Public Economics, 53(1): $91-110$.

Kast, Felipe, Stephan Meier, and Dina Pomeranz. 2012. "Under-savers anonymous: Evidence on self-help groups and peer pressure as a savings commitment device." NBER Working Paper 18417.

Kaur, Supreet, Michael Kremer, and Sendhil Mullainathan. 2010. "Self-Control and the Development of Work Arrangements." American Economic Review, 100(2): 624-28.

Milkman, Katherine L., Julia A. Minson, and Kevin GM Volpp. 2013. "Holding the Hunger Games hostage at the gym: An evaluation of temptation bundling." Management science, 60(2): 283-299.

Milkman, Katherine L., Todd Rogers, and Max H. Bazerman. 2008. "Harnessing our inner angels and demons: What we have learned about want/should conflicts and how that knowledge can help us reduce short-sighted decision making." Perspectives on Psychological Science, 3(4): 324-338.

Nagin, Daniel S., James B. Rebitzer, Seth Sanders, and Lowell J. Taylor. 2002. "Monitoring, Motivation, and Management: The Determinants of Opportunistic Behavior in a Field Experiment." American Economic Review, 92(4): 850-873.

O'Donoghue, Ted, and Matthew Rabin. 1999. "Doing It Now or Later." American Economic Review, 89(1): 103-124.

Peysakhovich, Alexander. 2014. "How to commit (if you must): Commitment contracts and the dual-self model." Journal of Economic Behavior \& Organization, 101: 100-112.

Strotz, Robert Henry. 1955. "Myopia and inconsistency in dynamic utility maximization." The Review of Economic Studies, 165-180.

Thaler, Richard H, and Shlomo Benartzi. 2004. "Save more tomorrow?: Using behavioral economics to increase employee saving." Journal of Political Economy, 112(S1): S164S187. 


\section{Appendix A}

Table A.1: Regression Results for Public and Private Treatments

\begin{tabular}{|c|c|c|c|c|c|c|c|c|}
\hline \multirow[b]{3}{*}{ Public } & \multicolumn{4}{|c|}{ 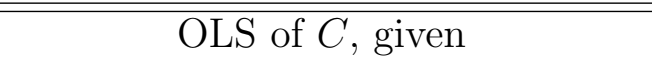 } & \multicolumn{4}{|c|}{ Probit (marginal effects shown) of } \\
\hline & \multicolumn{2}{|c|}{ any $C$} & \multicolumn{2}{|c|}{$C>0$} & \multicolumn{2}{|c|}{$1(C>0)$} & \multicolumn{2}{|c|}{$1(C=15)$} \\
\hline & $\begin{array}{l}3.699^{* *} \\
(1.814)\end{array}$ & $\begin{array}{l}4.712^{* *} \\
(2.015)\end{array}$ & $\begin{array}{c}1.250 \\
(1.364)\end{array}$ & $\begin{array}{c}1.953 \\
(1.781)\end{array}$ & $\begin{array}{l}0.225^{* *} \\
(0.114)\end{array}$ & $\begin{array}{l}0.303^{* * *} \\
(0.108)\end{array}$ & $\begin{array}{l}0.231^{* *} \\
(0.113)\end{array}$ & $\begin{array}{l}0.319^{* * *} \\
(0.111)\end{array}$ \\
\hline Constant & $\begin{array}{l}5.172^{\text {*** }} \\
(1.304)\end{array}$ & $\begin{array}{l}-0.933 \\
(6.721)\end{array}$ & $\begin{array}{l}12.500^{* *} \\
(1.079)\end{array}$ & $\begin{array}{l}13.378^{\text {** }} \\
(4.401)\end{array}$ & & & & \\
\hline Observations & 60 & 60 & 32 & 32 & 60 & 58 & 60 & 60 \\
\hline Controls & no & yes & no & yes & no & yes & no & yes \\
\hline
\end{tabular}

${ }^{*} p<0.10,{ }^{* *} p<0.05,{ }^{* * *} p<0.01$. Public is an indicator for being in the public treatment. Controls include a count of how many workshops an individual signed-up for, and workshop fixed effects. The data set is the 60 students in the private or public treatments.

Figure A.1: Example screenshot of study intervention page for control treatment

Thank you for signing up to attend and please note on your calendar the following Haas Center Workshop:

\section{Name of Workshop \\ Date of Workshop, from start time to end time Haas Center Room X}

Since you are now recorded as signing-up for the above workshop, you may exit from this page, if you wish. Or, you may take advantage of the following grant opportunity.

A grant has provided funding for the following promotion. Within one week of the workshop listed above, you will be emailed an Amazon gift card worth the following amount:

$\$ 15$.

Note that you will receive the corresponding Amazon gift card via email within one week AFTER the workshop date. Please push the arrow to COMPLETE this survey.

Note that the workshop title, date, time, and location were provided when students viewed this page. 
Figure A.2: Example screenshot of study intervention page for private treatment

Thank you for signing up to attend and please note on your calendar the following Haas Center Workshop:

\section{Name of Workshop \\ Date of Workshop, from start time to end time Haas Center Room X}

Since you are now recorded as signing-up for the above workshop, you may exit from this page, if you wish. Or, you may take advantage of the following grant opportunity.

A grant has provided funding for the following promotion. Within one week of the workshop listed above, you will be emailed an Amazon gift card worth the following amount:

\section{$\$ 15$ if you ATTEND this workshop, or \\ \$X if you DO NOT ATTEND this workshop}

*Please choose what value you would like for $\mathbf{X}$ below.

Note that your chosen value of $X$ will NOT be shared with anyone involved with running the Haas Center Workshops. That is, your chosen value of $X$ will be kept anonymous. Also, please note that the granting institution, and NOT the Haas Center, will retain any money left over from this $\$ 15$.

$$
\begin{array}{lllllllllllllll}
\$ 0 & \$ 1 & \$ 2 & \$ 3 & \$ 4 & \$ 5 & \$ 6 & \$ 7 & \$ 8 & \$ 9 & \$ 10 & \$ 11 & \$ 12 & \$ 13 & \$ 14
\end{array}
$$

Note that you will receive the corresponding Amazon gift card via email within one week AFTER the workshop date. Please push the arrow to COMPLETE this survey.

Note that the workshop title, date, time, and location were provided when students viewed this page. 
Figure A.3: Example screenshot of study intervention page for public treatment

Thank you for signing up to attend and please note on your calendar the following Haas Center Workshop:

\author{
Name of Workshop \\ Date of Workshop, from start time to end time \\ Haas Center Room X
}

Since you are now recorded as signing-up for the above workshop, you may exit from this page, if you wish. Or, you may take advantage of the following grant opportunity.

A grant has provided funding for the following promotion. Within one week of the workshop listed above, you will be emailed an Amazon gift card worth the following amount:

\title{
\$15 if you ATTEND this workshop, or \\ \$X if you DO NOT ATTEND this workshop
}

*Please choose what value you would like for $X$ below.

Note that your name and your chosen value of $X$ will be shared in a Haas Center Report and with who organizes Haas Center Workshops and is the Program Director of Student Organizations \& Leadership at the Haas Center. Also, please note that the granting institution, and NOT the Haas Center, will retain any money left over from this $\$ 15$.

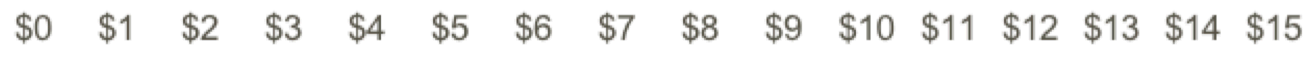

Note that you will receive the corresponding Amazon gift card via email within one week AFTER the workshop date. Please push the arrow to COMPLETE this survey.

Note that the workshop title, date, time, and location were provided when students viewed this page. 